\title{
Rescue ALPPS is efficient and safe after failed portal vein occlusion in patients with colorectal liver metastases
}

\author{
Ernesto Sparrelid $^{1,2}$ (I) $\cdot$ Stefan Gilg $^{1} \cdot$ Torkel B. Brismar $^{3} \cdot$ Lars Lundell $^{1}$. \\ Bengt Isaksson ${ }^{1}$
}

Received: 15 April 2016/Accepted: 7 October 2016 /Published online: 19 October 2016

(C) The Author(s) 2016. This article is published with open access at Springerlink.com

\begin{abstract}
Purpose The aim of this study was to investigate whether associating liver partition and portal vein ligation for staged hepatectomy (ALPPS) can be used as an effective and safe rescue procedure in patients with colorectal liver metastases (CRLM) and insufficient effect on the future liver remnant (FLR) after previous portal vein occlusion (PVO).

Methods Eleven patients with bilobar CRLM treated with neoadjuvant chemotherapy and previous PVO with insufficient effect on the FLR were analyzed retrospectively from a prospective database. FLR was evaluated with computed tomography volumetry 6 days after stage 1 , and stage 2 was performed on day seven.

Results Six days after stage 1, the median increase of the FLR was $209 \mathrm{ml}$ (range 87-314, $P<0.001$ ). This corresponded to a median FLR growth of $61.8 \%$ (range 19.3-120) resulting in an FLR/BW ratio $>0.5 \%$ in all patients and successful subsequent removal of the tumor bearing liver (segments IV-VIII) in all patients with no 90-day mortality. No patient had a 3bcomplication or more according to Clavien-Dindo. No patient developed severe posthepatectomy liver failure.
\end{abstract}

Ernesto Sparrelid

ernesto.sparrelid@ki.se

1 Division of Surgery, Department of Clinical Science, Intervention, and Technology (CLINTEC), Center for Digestive Diseases, Karolinska University Hospital, Karolinska Institutet, Stockholm, Sweden

2 Department of Surgery, Centre for Digestive Diseases, Karolinska University Hospital, Stockholm, Sweden

3 Division of Radiology, Department of Clinical Science, Intervention, and Technology (CLINTEC), Karolinska University Hospital,

Karolinska Institutet, Stockholm, Sweden
Conclusions The powerful hypertrophy of the FLR associated with ALPPS seems to be maintained in patients with CRLM and previous failed PVO.

Keywords Liver resection · Colorectal liver metastases . ALPPS · PVO

\section{Introduction}

Portal vein occlusion (PVO) by either selective embolization (PVE) or ligation (PVL) of the portal vein to the tumor bearing part of the liver is an established method to increase the size of the future liver remnant (FLR) [1,2]. The main purpose of this procedure is to convert previously unresectable patients to resection candidates by achieving sufficient size of the FLR before hepatectomy, in order to avoid posthepatectomy liver failure (PHLF) [3].

However, it has to be recalled that about one third of the patients submitted to PVO eventually never undergo a curative resection due to either insufficient growth of the FLR with an unacceptable risk of PHLF if submitted to surgery, or they progress to an unresectable local tumor situation while awaiting the full PVO effect $[4,5]$.

Associating liver partition and portal vein ligation for staged hepatectomy (ALPPS) has rendered great attention since its introduction $[6,7]$. Although showing promising results with unprecedented growth of FLR, both in time and size, the technique has also been subjected to criticism, mainly because of high morbidity and mortality rates $[8,9]$. A recent review of the literature shows that the majority of the serious complications affect patients subjected to concomitant biliary surgery $[6,10,11]$, while patients with colorectal liver metastases (CRLM) undergoing ALPPS seem to be less prone to develop high-grade complications [11]. In an attempt to address patients with insufficient 
growth of the FLR after PVO, a modified ALPPS with only parenchymal transection ("rescue" ALPPS) has been reported in a few small case series [12-15].

The aim of this study was to investigate whether ALPPS can be used as an effective and safe rescue procedure in patients with CRLM and insufficient effect on the FLR after previous PVO.

\section{Material and methods}

\section{Patients}

From November 2012 to June 2015, 11 patients were included in the study from a prospective database at the Center for Digestive Diseases at Karolinska University Hospital. All patients presented with bilobar CRLM and had been treated with neoadjuvant chemotherapy. The patients were previously subjected to PVO (PVE, PVL, or both) with insufficient effect on the FLR and subsequently operated with rescue ALPPS. All patients were discussed at the local MDT conference. A ratio between FLR and body weight (FLR/BW ratio) of less than $0.5 \%$ was considered as an indication for ALPPS [16]. Six days after stage 1, FLR was evaluated with computed tomography $(\mathrm{CT})$ volumetry and stage 2 was performed on day seven. All patients had bilobar tumor manifestation but only four had metastases in segment I, II, or III requiring tumor clearance of the FLR at stage 1 (the remaining had metastases in segment IV in addition to the tumors in the right liver lobe). All patients were treated with neoadjuvant chemotherapy with a median of seven cycles (range 4-14). The treatment agents consisted of FOLFOX or FOLFIRI +/- a biological agent. The time elapsed from completion of chemotherapy treatment to stage 1 operation in the study was in median 85 days (range 26-172), as a result of the waiting time from PVO to ALPPS given the fact that chemotherapy was not given after PVO. The clinicopathological characteristics of the patient cohort are presented in detail in Table 1.

\section{Surgical technique}

PVE was performed with percutaneous ipsilateral technique and puncture of peripheral portal branches of the right side. Polyvinyl alcohol beads (Terumo Bead Block ${ }^{\mathrm{TM}}$ Embolic Bead, Metron Healthcare, Athens, Greece) and polyvinyl alcohol particles (Contour ${ }^{\mathrm{TM}}$, Boston Scientic, Cork, Ireland) were combined with central coils (MicroNester ${ }^{\circledR}$ Embolization Coil, Cook, Indianapolis, USA), placed in the right portal vein, to obtain occlusion of the portovenous system to segment V-VIII. The portal branches to segment IV were not embolized as this is not routine at our center. PVL was performed by division of the right portal vein using a stapler instrument (Endo GIA ${ }^{\mathrm{TM}}$ Universal with TriStaple $^{\mathrm{TM}}$, Covidien, Dublin, Ireland). PVL was preferred over
PVE only when the FLR contained metastases and used together with local resections in FLR in the stage 1 operation of an intended conventional two-stage hepatectomy. ALPPS was performed in a similar way as described previously [6] in the patients with failed PVE. In summary, stage 1 comprised of division of the right portal vein as in PVL and complete parenchymal transection to the right of the falciform ligament using cavitron ultrasonic surgical aspirator (CUSA $®$, Valleylab Inc., Boulder, CO, USA). In rescue ALPPS after failed PVL, only parenchymal transection was performed at stage 1 . At stage 2, performed 7 days later in all patients, the right portal pedicle and right liver vein were divided using the same stapler instrument as above and the tumor bearing deportalized liver could be removed as in an extended rightsided hemihepatectomy preserving only segment I-III in all patients.

\section{Volumetric analysis}

Liver volume was calculated from a four-phase contrast enhanced CT of the liver by using the software Volume Viewer@ (Voxtool 11.x) for AW Volume Share 5 implemented on an AW Workstation (GE Healthcare, Fairfield, CT, USA). The CT evaluating the effect of the PVO was performed after 28 days in median (range 19-33) and was used as baseline investigation (Table 1). To measure the effect on the FLR, all patients underwent a second CT of the liver on day six after stage 1 (Fig. 1). The FLR/BW ratio was calculated and total estimated liver volume (TELV) was calculated according to the formula developed by Vauthey and co-workers to obtain standardized FLR (sFLR) [17].

\section{Data collection and statistical analysis}

Baseline patient characteristics, volumetric data, procedural data, and complications were collected prospectively in a local database. Statistical analysis was performed using JMP® version 5.1 (SAS Institute Inc., Cary, NC, USA). Median values (range) were used for continuous variables whereas frequencies were calculated for categorical variables. Paired $t$ test was used to compare means between different time points in the same patient. $P$ values of $<0.05$ were considered to represent statistical significance.

The study protocol was approved by the Central Ethical Review Board, Stockholm, Sweden.

\section{Results}

\section{Clinical outcome}

The median operating time for stage 1 was 282 min (range 200-398) with an intraoperative blood loss of $1500 \mathrm{ml}$ (range 
Table 1 Clinicopathological characteristics of the patient cohort $(n=11)$ before ALPPS

\begin{tabular}{|c|c|}
\hline Variable & Rescue ALPPS $(n=11)$ \\
\hline Median age, years (range) & $67(41-74)$ \\
\hline Male/female gender & $8 / 3$ \\
\hline Median BMI (range) & $26.1(22.2-29.4)$ \\
\hline ASA-class $1-2$ & 9 \\
\hline ASA-class 3 & 2 \\
\hline Synchronous/metachronous metastases & $6 / 5$ \\
\hline Median number of liver metastases (range) & $7(2-20)$ \\
\hline \multicolumn{2}{|l|}{ Tumor localization } \\
\hline Right lobe + segment 4 & 7 \\
\hline Right lobe + segment $4+$ left lateral segment & 4 \\
\hline \multicolumn{2}{|l|}{ Chemotherapy before ALPPS } \\
\hline Oxaliplatin based & 7 \\
\hline Irinotecan based & 4 \\
\hline Targeted therapy & 5 \\
\hline Number of chemotherapy cycles (range) & $7(4-14)$ \\
\hline Days between chemo and ALPPS (range) & $85(26-172)$ \\
\hline \multicolumn{2}{|l|}{ Portal vein occlusion prior to ALPPS } \\
\hline Portal vein embolization (PVE) & 5 \\
\hline Portal vein ligation (PVL) & 4 \\
\hline First PVL then PVE & 2 \\
\hline TELV, ml (range) & $1651(1436-2070)$ \\
\hline FLR before PVO, ml (range) & $250(180-370)$ \\
\hline FLR/BW ratio before $\mathrm{PVO}, \%$ (range) & $0.33(0.25-0.40)$ \\
\hline sFLR before PVO, \% (range) & $14.9(11.9-19.7)$ \\
\hline Growth of FLR after PVO, \% (range) & $26.8(-7.3-66.7)$ \\
\hline Days from PVO to CT & $28(19-33)$ \\
\hline FLR before ALPPS, ml (range) & $312(260-450)$ \\
\hline FLR/BW ratio before ALPPS, $\%$ (range) & $0.41(0.35-0.49)$ \\
\hline sFLR before ALPPS, $\%$ (range) & $18.7(16.1-23.8)$ \\
\hline
\end{tabular}

ASA American Society of Anesthesiologists Physical Classification System, TELV total estimated liver volume, $F L R$ future liver remnant, $s F L R$ standardized FLR, FLR/BW ratio FLR to body weight ratio
400-5600). In the four patients requiring tumor clearance of the FLR, local resections were performed in two patients, and in two patients, a combination of local resections and microwave ablation (MWA) was used. All these procedures for metastases in the FLR were undertaken during the stage 1 procedure. All patients could complete stage 2 with the removal of the tumor bearing deportalized liver. Radical resection (R0) was achieved in all 11 patients. The complication rate was low. Four patients had pleural effusion that was drained in local anesthesia, consequently recorded as a $3 \mathrm{a}$-complication according to the Clavien-Dindo classification [18, 19]. In one patient, this occurred after stage 1 and in the remaining three after stage 2 . There were no complications equal to or above $3 \mathrm{~b}$. No patient fulfilled the Balzan 50/50 [20], peak bilirubin $>7$ [21], or ISGLS [22] criteria grade
C for severe postoperative liver failure and there was no 90-day mortality. Detailed postoperative clinical data are shown in Table 2.
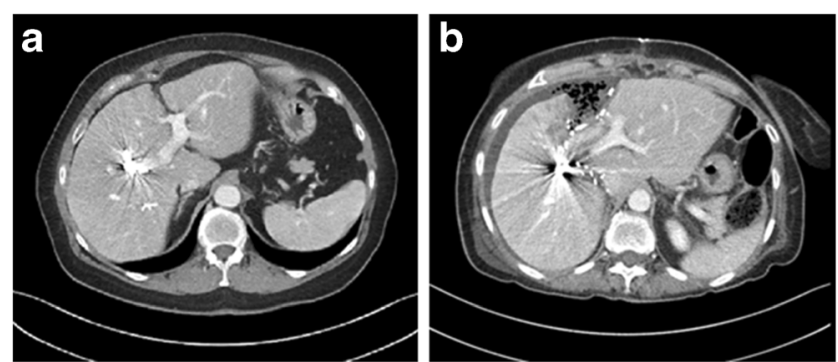

Fig. 1 Example of rescue ALPPS after failed portal vein embolization CT after PVE (a) and CT before stage 2 (b) in the same patient 


\section{Growth of the FLR}

FLR volume before PVO was $250 \mathrm{ml}$ (range 180-370). After PVO the FLR increased to $312 \mathrm{ml}$ (range 260450), representing a growth of the FLR with $26.8 \%$ (range $-7.3-66.7, P=0.006$ ). All patients responded well to the ALPPS stage 1 procedure despite previous PVO. Six days after stage 1 , the median increase of the FLR was $209 \mathrm{ml}$ (range 87-314, $P<0.001$ ). This corresponded to an increase of FLR/BW ratio to $0.69 \%$ (range $0.59-0.81$ ), i.e., reaching more than $0.5 \%$ in all patients (Fig. 2a). In Fig. $2 b$, the corresponding increase in SFLR is also presented. The growth of the FLR between stage 1 and 2 was in median $61.8 \%$ (range 19.3-120). For further details regarding volumetrical data, see Tables 1 and 2.

\section{Discussion}

This study confirms results from previous smaller case reports that ALPPS can be both safe and effective as a rescue procedure in CRLM patients with insufficient effect on the FLR after previous PVO. In addition, it seems as if the previously described high morbidity and mortality associated with ALPPS does not apply when performing the procedure in this patient group.

As mentioned, rescue ALPPS for CRLM has been described previously [12-15], although in only quite few patients. Despite the limited number of patients enrolled, the patient cohort of this study still represents the largest series of rescue ALPPS for CRLM so far presented, and in addition, the main aim of this study was to specifically investigate rescue ALPPS. In one recent study [15], nine patients with ALPPS after PVE were reported but without stating the background diagnosis and chemotherapy regimens in those subjected to PVE before ALPPS. Some of the patients in the present study were also included in a Scandinavian multicenter study recently published [23]. However, this study also reported a mixed study population and did not have the aim to study rescue ALPPS. To analyze the effect and consequences of a complex procedure such as ALPPS, we considered it as an advantage to have a patient population as homogenous as possible to minimize the effects of a variety of confounding factors. Accordingly, we only included patients with bilobar CRLM; all of them subjected to neoadjuvant chemotherapy and with an FLR consisting of segment I-III in all patients.

In the present study cohort, the overall median growth of the FLR before stage 2 was $61.8 \%$, which is less than reported in most previous studies. This might, however, be explained by two factors. Firstly, in contrast to the majority of other reports on ALPPS, only patients with CRLM treated with pre-procedural chemotherapy were included. It is recognized that pre-PVE chemotherapy can have a negative effect on growth of the FLR after PVE $[24,25]$ and it is likely to have the same effect after ALPPS, although this remains to be proven. Another
Table 2 Procedural, clinical, and volumetrical data after completed ALPPS

\begin{tabular}{ll}
\hline Variable & Rescue ALPPS $(n=11)$ \\
\hline Operating time stage 1, min (range) & $282(200-398)$ \\
Bleeding during stage 1, ml (range) & $1500(400-5600)$ \\
Completed stage 2 & 11 \\
R0-resection & 11 \\
Complication (Clavien-Dindo) 3a & 4 \\
Complication (Clavien-Dindo) $\geq 3 \mathrm{~b}$ & 0 \\
Fulfills Balzan criteria & 0 \\
90-day mortality & 0 \\
FLR after stage 2, ml (range) & $557(395-619)$ \\
FLR/BW ratio before stage 2, $\%$ (range) & $0.69(0.59-0.81)$ \\
sFLR before stage 2, $\%$ (range) & $31.2(27.5-36)$ \\
Growth of FLR between stage 1 and 2, \% (range) & $61.8(19.3-120)$ \\
PK (INR) 1 day before stage 1 & $1.0(0.9-1.1)$ \\
PK (INR) 5 days after stage 1 & $1.2(1.1-1.5)$ \\
PK (INR) 5 days after stage 2 & $1.3(1.2-1.8)$ \\
Bilirubin 1 day before stage 1 & $6(3-14)$ \\
Bilirubin 5 days after stage 1 & $8(6-22)$ \\
Bilirubin 5 days after stage 2 & $17(8-49)$ \\
\hline R0-resection
\end{tabular}

R0-resection radical resection with $>1 \mathrm{~mm}$ margin, $P K(I N R)$ normal if $<1.2$, Bilirubin normal if $<26$ micromol/1 
Fig. 2 Box-whisker plot displaying the increase in FLR/ BW ratio (a) and sFLR (b) between stage 1 and 2 of ALPPS in patients subjected to rescue ALPPS. a Increase in FLR/BW ratio. Dotted red line shows $0.5 \%$. b Increase in sFLR. Dotted red line shows $30 \%$
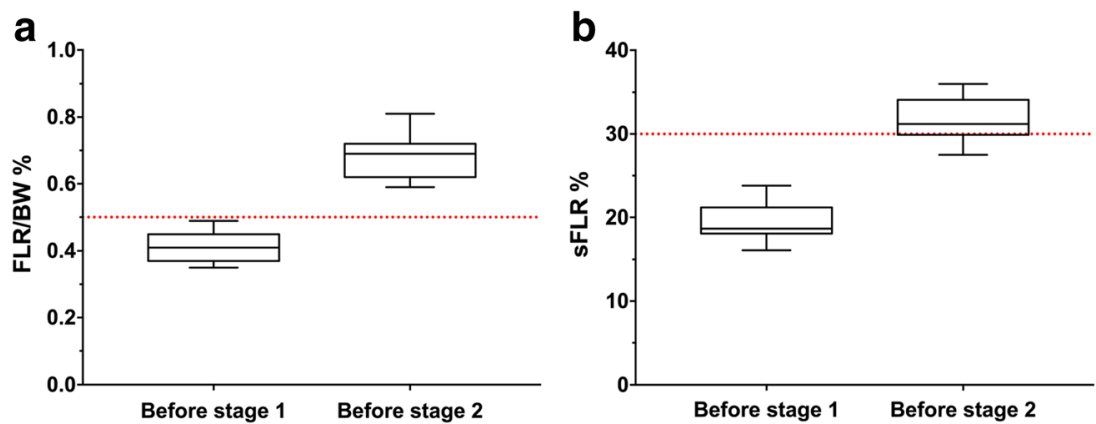

complicating factor was that the interval between the cessation of chemotherapy and ALPPS was quite long due to the waiting time from PVO to ALPPS. Consequently, the alleged negative effect of pre-procedural chemotherapy on FLR hypertrophy might have been less pronounced in these patients compared to the patients undergoing ALPPS without previous PVO. Secondly, the inter-stage time of 7 days used for all patients in this study was shorter than in the most published series [26]. That might in part explain the somewhat less pronounced hypertrophy rate. Also, the volume increase of the FLR seems to be paired with a functional increase since no patient developed severe liver failure after stage 2. This absence of severe PHLF was seen despite the fact that a FLR/BW ratio below $0.5 \%$ was used for inclusion, compared to other centers that use a FLR/BW ratio below $0.8 \%$ or a sFLR below $30 \%$ for deciding to perform ALPPS in patients with pre-procedural chemotherapy [27, 28]. In a recent retrospective study at our institution comparing different volumetric methods for characterizing the size of the FLR before and after PVE, an FLR/BW ratio of $0.5 \%$ corresponded to a sFLR of $22.9 \%$ and thus clearly below sFLR of $30 \%$ (unpublished data).

The observed low morbidity and zero mortality are probably attributed to the inclusion of only patients with CRLM as mentioned above. In the first publication from the ALPPS Registry, age above 60 years was reported as a risk factor for mortality after ALPPS in CRLM [11]. The median age in this study population was 67 years, but we speculate that our low patient co-morbidity might have contributed to the absence of 90-day mortality. The resection rate in this study was $100 \%$, similar or higher to what has been achieved in previous studies, which clearly surpasses the resection rate after PVO and twostage hepatectomy [29]. A potential confounder might be that some patients subjected to $\mathrm{PVO}$ will experience tumor progression while waiting for the effect of the PVO excluding them from subsequent surgery, thus leading to a possible selection bias with a more favorable tumor situation for patients undergoing rescue ALPPS compared to those submitted directly to standard ALPPS.
The question whether ALPPS should be used more frequently in patients with CRLM and a small FLR remains to be answered. In this study, ALPPS was used successfully as a rescue method after failed PVO. Considering the potent growth of the FLR after ALPPS, patients with CRLM and very small FLR and/ or monosegment FLR should probably be considered for ALPPS upfront [30].

\section{Conclusion}

The powerful FLR growth associated with ALPPS seems to remain even when performed in patients with previous PVO. Apparently, in patients with colorectal liver metastases subjected to previous PVO, ALPPS can be performed with low morbidity and high resection rate.

Authors' contributions Study conception and design-ES, LL, BI

Acquisition of data-ES, SG, TB

Analysis and interpretation of data-ES, BI

Drafting manuscript-ES

Critical revision of manuscript—SG, TB, LL, BI

Compliance with ethical standards The study protocol was approved by the Central Ethical Review Board, Stockholm, Sweden.

Conflict of interest The authors declare that they have no conflicts of interest.

Ethical approval All procedures performed in studies involving human participants were in accordance with the ethical standards of the institutional research committee and with the 1964 Helsinki Declaration and its later amendments or comparable ethical standards.

Informed consent Informed consent was obtained from all individual participants included in the study.

Open Access This article is distributed under the terms of the Creative Commons Attribution 4.0 International License (http:// creativecommons.org/licenses/by/4.0/), which permits unrestricted use, distribution, and reproduction in any medium, provided you give appropriate credit to the original author(s) and the source, provide a link to the Creative Commons license, and indicate if changes were made. 


\section{References}

1. Abulkhir A, Limongelli P, Healey AJ, Damrah O, Tait P, Jackson J, Habib N, Jiao LR (2008) Preoperative portal vein embolization for major liver resection: a meta-analysis. Ann Surg 247(1):49-57. doi:10.1097/SLA.0b013e31815f6e5b

2. Pandanaboyana S, Bell R, Hidalgo E, Toogood G, Prasad KR, Bartlett A, Lodge JP (2015) A systematic review and metaanalysis of portal vein ligation versus portal vein embolization for elective liver resection. Surgery 157(4):690-698. doi:10.1016/j. surg.2014.12.009

3. Hemming AW, Reed AI, Howard RJ, Fujita S, Hochwald SN, Caridi JG, Hawkins IF, Vauthey JN (2003) Preoperative portal vein embolization for extended hepatectomy. Ann Surg 237(5):686-691 . doi:10.1097/01.sla.0000065265.16728.c0discussion 691-683

4. Jaeck D, Oussoultzoglou E, Rosso E, Greget M, Weber J-C, Bachellier P (2004) A two-stage hepatectomy procedure combined with portal vein embolization to achieve curative resection for initially unresectable multiple and bilobar colorectal liver metastases. Ann Surg 240(6): 1037-1051. doi:10.1097/01.sla.0000145965.86383.89

5. Kianmanesh R, Farges O, Abdalla EK, Sauvanet A, Ruszniewski P, Belghiti J (2003) Right portal vein ligation: a new planned two-step all-surgical approach for complete resection of primary gastrointestinal tumors with multiple bilateral liver metastases. J Am Coll Surg 197(1):164-170. doi:10.1016/S1072-7515(03)00334-X

6. Schnitzbauer AA, Lang SA, Goessmann H, Nadalin S, Baumgart J, Farkas SA, Fichtner-Feigl S, Lorf T, Goralcyk A, Horbelt R, Kroemer A, Loss M, Rummele P, Scherer MN, Padberg W, Konigsrainer A, Lang H, Obed A, Schlitt HJ (2012) Right portal vein ligation combined with in situ splitting induces rapid left lateral liver lobe hypertrophy enabling 2-staged extended right hepatic resection in small-for-size settings. Ann Surg 255(3):405-414. doi:10.1097/SLA.0b013e31824856f5

7. de Santibanes E, Alvarez FA, Ardiles V (2012) How to avoid postoperative liver failure: a novel method. World J Surg 36(1):125128. doi:10.1007/s00268-011-1331-0

8. Aloia TA, Vauthey JN (2012) Associating liver partition and portal vein ligation for staged hepatectomy (ALPPS): what is gained and what is lost? Ann Surg 256(3):e9 . doi:10.1097/SLA.0b013 e318265fd3eauthor reply e16-19

9. Kokudo N, Shindoh J (2013) How can we safely climb the ALPPS? Updat Surg 65(3):175-177. doi:10.1007/s13304-013-0215-2

10. Nadalin S, Capobianco I, Li J, Girotti P, Konigsrainer I, Konigsrainer A (2014) Indications and limits for associating liver partition and portal vein ligation for staged hepatectomy (ALPPS). Lessons learned from 15 cases at a single centre. Zeitschrift fur Gastroenterologie 52(1):35-42. doi:10.1055/s-0033-1356364

11. Schadde E, Ardiles V, Robles-Campos R, Malago M, Machado M, Hernandez-Alejandro R, Soubrane O, Schnitzbauer AA, Raptis D, Tschuor C, Petrowsky H, De Santibanes E, Clavien PA, Group AR, Abdalla E, Adam R, Alden D, Aldrighetti LA, de Paz EA, Balzan S, Barkun J, Bjornsson B, Castro-Benitez C, Chapman WC, Chardarov N, Chaychenko D, Cherqui D, Corradetti L, Croome K, Cugat E, Dong J, Donckier V, Doussot A, Enne M, Figueras J, Fonollosa EH, Gauzolino R, Gruenberger T, Keutgen XM, Koffron A, Kukudo N, Lendoire J, Lodge JP, Logan S, Lorenzin D, Lucidi V, Lurje G, Masetti M, McCormack L, Montalti R, Nagino M, Nussler N, Ortega-Deballon P, Pineda K, Pissanou T, Ratti F, Regimbeau JM, Rogiers X, Sakamoto Y, Sandstrom P, Santoyo J, Scatton O, Sergeant G, Serrablo A, Sharma D, Skipenko O, Solomonov E, Sparrelid E, Stojanovic S, Strassberg S, Torrenga H, Troisi R, Truant S, Vacharajani N, Viana de Carvalho E, Vibert E, Vicente E, Vivarelli M, Vyas S, Wen Z, Zheng W, Zhou J (2014) Early survival and safety of ALPPS: first report of the International
ALPPS Registry. Ann Surg 260(5):829-836 . doi:10.1097 SLA.0000000000000947discussion 836-828

12. Bjornsson B, Gasslander T, Sandstrom P (2013) In situ split of the liver when portal venous embolization fails to induce hypertrophy: a report of two cases. Case reports in surgery 2013:238675. doi:10.1155/2013/238675

13. Knoefel WT, Gabor I, Rehders A, Alexander A, Krausch M, Schulte am Esch J, Furst G, SA T (2013) In situ liver transection with portal vein ligation for rapid growth of the future liver remnant in two-stage liver resection. Br J Surg 100(3):388-394. doi:10.1002 /bjs. 8955

14. Tschuor C, Croome KP, Sergeant G, Cano V, Schadde E, Ardiles V, Slankamenac K, Claria RS, de Santibanes E, Hernandez-Alejandro R, Clavien PA (2013) Salvage parenchymal liver transection for patients with insufficient volume increase after portal vein occlusion - an extension of the ALPPS approach. Eur J Surg Oncol 39(11):1230-1235. doi:10.1016/j.ejso.2013.08.009

15. Truant S, Scatton O, Dokmak S, Regimbeau JM, Lucidi V, Laurent A, Gauzolino R, Castro Benitez C, Pequignot A, Donckier V, Lim C, Blanleuil ML, Brustia R, Le Treut YP, Soubrane O, Azoulay D, Farges O, Adam R, Pruvot FR, e HSGftAdCH-BedT (2015) Associating liver partition and portal vein ligation for staged hepatectomy (ALPPS): impact of the inter-stages course on morbimortality and implications for management. Eur J Surg Oncol 41(5):674-682. doi:10.1016/j.ejso.2015.01.004

16. Truant S, Oberlin O, Sergent G, Lebuffe G, Gambiez L, Ernst O, Pruvot FR (2007) Remnant liver volume to body weight ratio > or $=0.5 \%$ : a new cut-off to estimate postoperative risks after extended resection in noncirrhotic liver. J Am Coll Surg 204(1):22-33. doi:10.1016/j.jamcollsurg.2006.09.007

17. Ribero D, Chun YS, Vauthey JN (2008) Standardized liver volumetry for portal vein embolization. Semin Intervent Radiol 25(2):104-109. doi:10.1055/s-2008-1076681

18. Dindo D, Demartines N, Clavien P-A (2004) Classification of surgical complications. Ann Surg 240(2):205-213. doi:10.1097/01. sla.0000133083.54934.ae

19. Clavien PA, Barkun J, de Oliveira ML, Vauthey JN, Dindo D, Schulick RD, de Santibanes E, Pekolj J, Slankamenac K, Bassi C, Graf R, Vonlanthen R, Padbury R, Cameron JL, Makuuchi M (2009) The Clavien-Dindo classification of surgical complications: five-year experience. Ann Surg 250(2):187-196. doi:10.1097 /SLA.0b013e3181b13ca2

20. Balzan S, Belghiti J, Farges O, Ogata S, Sauvanet A, Delefosse D, Fo D (2005) The "50-50 criteria" on postoperative day 5: an accurate predictor of liver failure and death after hepatectomy. Ann Surg 242(6):824-829. doi:10.1097/01.sla.0000189131.90876.9e

21. Mullen JT, Ribero D, Reddy SK, Donadon M, Zorzi D, Gautam S, Abdalla EK, Curley SA, Capussotti L, Clary BM, Vauthey JN (2007) Hepatic insufficiency and mortality in 1 , 059 noncirrhotic patients undergoing major hepatectomy. J Am Coll Surg 204(5):854-862 . doi:10.1016/j. jamcollsurg.2006.12.032discussion 862-854

22. Rahbari NN, Garden OJ, Padbury R, Brooke-Smith M, Crawford M, Adam R, Koch M, Makuuchi M, Dematteo RP, Christophi C, Banting S, Usatoff V, Nagino M, Maddern G, Hugh TJ, Vauthey JN, Greig P, Rees M, Yokoyama Y, Fan ST, Nimura Y, Figueras J, Capussotti L, Buchler MW, Weitz J (2011) Posthepatectomy liver failure: a definition and grading by the International Study Group of Liver Surgery (ISGLS). Surgery 149(5):713-724. doi:10.1016/j. surg.2010.10.001

23. Rosok BI, Bjornsson B, Sparrelid E, Hasselgren K, Pomianowska E, Gasslander T, Bjornbeth BA, Isaksson B, Sandstrom P (2016) Scandinavian multicenter study on the safety and feasibility of the associating liver partition and portal vein ligation for staged hepatectomy procedure. Surgery 159(5):1279-1286. doi:10.1016/j. surg.2015.10.004 
24. de Baere T, Teriitehau C, Deschamps F, Catherine L, Rao P, Hakime A, Auperin A, Goere D, Elias D, Hechelhammer L (2010) Predictive factors for hypertrophy of the future remnant liver after selective portal vein embolization. Ann Surg Oncol 17(8):20812089. doi:10.1245/s10434-010-0979-2

25. Sturesson C, Hoekstra L, Andersson R, van Gulik TM (2015) Importance of thrombocytes for the hypertrophy response after portal vein embolization. Hepato-Gastroenterology 62(137):98-101

26. Hasselgren K, Sandstrom P, Bjornsson B (2015) Role of associating liver partition and portal vein ligation for staged hepatectomy in colorectal liver metastases: a review. World J Gastroenterol 21(15):4491-4498. doi:10.3748/wjg.v21.i15.4491

27. Alvarez FA, Ardiles V, Sanchez Claria R, Pekolj J, de Santibanes E (2013) Associating liver partition and portal vein ligation for staged hepatectomy (ALPPS): tips and tricks. J Gastrointest surg 17(4): 814-821. doi:10.1007/s11605-012-2092-2
28. Li J, Girotti P, Konigsrainer I, Ladurner R, Konigsrainer A, Nadalin S (2013) ALPPS in right trisectionectomy: a safe procedure to avoid postoperative liver failure? J Gastrointest Surg 17(5):956-961. doi:10.1007/s11605-012-2132-y

29. Schadde E, Hernandez-Alejandro R, Lang H, de Santibanes E, Clavien PA (2015) ALPPS offers a better chance of complete resection in patients with primarily unresectable liver tumors. Results of a multicentre analysis: reply. World J Surg 39(7):1850-1851. doi:10.1007/s00268-015-2964-1

30. Schadde E, Malago M, Hernandez-Alejandro R, Li J, Abdalla E, Ardiles V, Lurje G, Vyas S, Machado MA, de Santibanes E (2015) Monosegment ALPPS hepatectomy: extending resectability by rapid hypertrophy. Surgery 157(4):676-689. doi:10.1016/j. surg.2014.11.015 